\title{
Preparation and Quality Testing of Minor Element Series B of Japanese Standard Samples for Iron and Steel Analysis*
}

\section{By Sen-ichi HARIMAYA**}

\section{Introduction}

Advances of manufactural technique have given high-quality and variety of steel. Corresponding to this situation, much effort has been made for the expansion of kinds of standard samples, by taking the order of the importance and popularization of steels into consideration, at the Committee on Iron and Steel Standard Samples for Analysis.

The activities of the committee have been described in the booklet Progress of Japanese Standard Samples of Iron and Steel, published in commemoration of the 50th Convention. ${ }^{1)}$

The history and actual results of the committee have been mentioned in the Special Issue on Iron and Steel Analysis of Tetsu-to-Hagané. ${ }^{2) * * *}$ Annual reports and technical comments have also appeared in the pages of Committee News in Tetsu-to-Hagané.***

In this report, the production method and the technical inspection of production process are presented about the standard samples of Minor Element Series B, which have recently been produced.

\section{Standard Sample of Minor Element Series B}

This series has been produced for the purpose of expansion of kinds of Japanese Standard Samples for Iron and Steel Analysis and for control of quality of steel.

Four of the standard samples contain nickel, chromium, molybdenum, arsenic, tin, titanium and calcium with gradational concentrations, and other four contain vanadium, cobalt, aluminum, boron, ziroconium, niobium and antimony. Those are the first standard samples for calcium and antimony in Japan.

Chip samples are applicable for chemical analyses and disc samples ( $35 \mathrm{~mm} \phi \times 20 \mathrm{~mm}$ ), which constitute one set with the eight kinds, are for instrumental analyses. The chemical compositions of the samples for instrumental analyses are shown in Table 1.

The chemical compositions of samples for chemical analyses are different from those of the samples for instrumental analyses. (Refer to Tetsu-to-Hagané, 60 (1974), N245).

Table 1. Chemical composition of Minor Element Series B (\%)

\begin{tabular}{|c|c|c|c|c|c|c|c|c|}
\hline Element & $\underset{168-1}{J S S}$ & $\begin{array}{c}\text { JSS } \\
169-1\end{array}$ & $\begin{array}{l}\text { JSS } \\
170-1\end{array}$ & $\begin{array}{l}\text { JSS } \\
171-1\end{array}$ & $\begin{array}{l}\text { JSS } \\
172-1\end{array}$ & $\begin{array}{c}\text { JSS } \\
173-1\end{array}$ & $\underset{174-1}{\text { JSS }}$ & $\underset{175-1}{J S S}$ \\
\hline C & 0.055 & 0.054 & 0.062 & 0.081 & 0.081 & 0.079 & 0.071 & 0.083 \\
\hline $\mathrm{Si}$ & $(0.24)$ & $(0.21)$ & $(0.20)$ & $(0.20)$ & $(0.21)$ & $(0.21)$ & $(0.21)$ & $(0.21)$ \\
\hline $\mathrm{Mn}$ & $(0.41)$ & $(0.41)$ & $(0.42)$ & $(0.42)$ & $(0.42)$ & $(0.42)$ & $(0.41)$ & $(0.41)$ \\
\hline $\mathrm{P}$ & $(0.005)$ & $(0.005)$ & $(0.005)$ & $(0.003)$ & $(0.004)$ & $(0.003)$ & $(0.003)$ & $(0.003)$ \\
\hline $\mathrm{S}$ & $(0.013)$ & $(0.010)$ & $(0.009)$ & $(0.009)$ & $(0.008)$ & $(0.009)$ & $(0.009)$ & $(0.009)$ \\
\hline $\mathrm{Ni}$ & 0.013 & 0.038 & 0.070 & 0.100 & & & & \\
\hline $\mathrm{Cr}$ & 0.012 & 0.094 & 0.037 & 0.067 & & & & \\
\hline Mo & 0.095 & 0.067 & 0.011 & 0.038 & & & & \\
\hline V & & & & & 0.010 & 0.035 & 0.062 & 0.093 \\
\hline Co & & & & & 0.055 & 0.030 & 0.020 & 0.010 \\
\hline $\mathrm{Ti}$ & 0.065 & 0.013 & 0.097 & 0.038 & & & & \\
\hline $\mathrm{Al}$ & 0.047 & 0.046 & 0.049 & 0.052 & 0.015 & 0.024 & 0.032 & 0.054 \\
\hline As & 0.010 & 0.005 & 0.028 & 0.046 & & & & \\
\hline Sn & 0.005 & 0.011 & 0.053 & 0.032 & & & & \\
\hline B & & & & & 0.0021 & 0.0031 & 0.0052 & 0.0085 \\
\hline $\mathrm{Nb}$ & & & & & 0.053 & 0.032 & 0.021 & 0.011 \\
\hline $\mathrm{Zr}$ & & & & & 0.009 & 0.019 & 0.028 & 0.048 \\
\hline $\mathrm{Sb}$ & & & & & 0.0019 & 0.0047 & 0.0100 & 0.019 \\
\hline $\mathrm{Ca}$ & 0.0007 & 0.0013 & 0.0017 & 0.0027 & & & & \\
\hline $\mathrm{Fe}$ & $(99.0)$ & $(99.0)$ & $(98.9)$ & $(98.9)$ & $(99.1)$ & $(99.1)$ & $(99.1)$ & $(99.0)$ \\
\hline
\end{tabular}

( ): Uncertified value

* Originally published in Tetsu-to-Hagané, 64 (1978), 155, in Japanese. English version received September 19, 1978.

** Committee on Iron and Steel Standard Samples for Analysis, The Iron and Steel Institute of Japan, Otemachi, Chiyoda-ku, Tokyo 100.

*** Journal of The Iron and Steel Institute of Japan (in Japanese). 


\section{Production Method}

The outline of the production process of the standard samples is shown in Fig. 1. Ingots containing objective elements were melted to product from electrolytic iron in a vacuum melting furnace. The ingots were forged into the scraps of $120 \mathrm{~mm}$ cube (the primary sample).

The top and bottom of the primary sample were then cut off and ground to remove the decarbonized layer and forging cracks.

The suitable parts for standard samples were selected through the results of segregation tests, i.e.,

Cut the top and bottom of ingot sample, and grind or peel the surface layer.

Sulfur print.

Macroscopic test.

Analysis of main elements. sulfur print, microscopic test and chemical analysis.

The chips for chemical analysis were prepared from the primary sample by removing the segregation part.

The segregation part of a disc for instrumental

Special melting steel
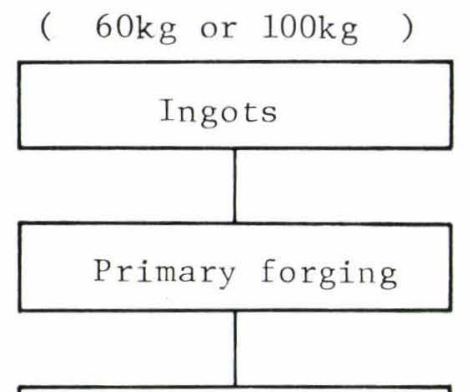

Cutting and Grinding

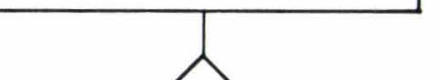

For chemical analysis

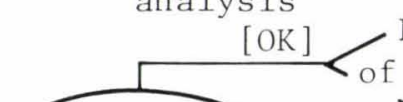

Estimation

For instrumental analysis

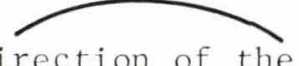

Direction of the part to be whittled after each test
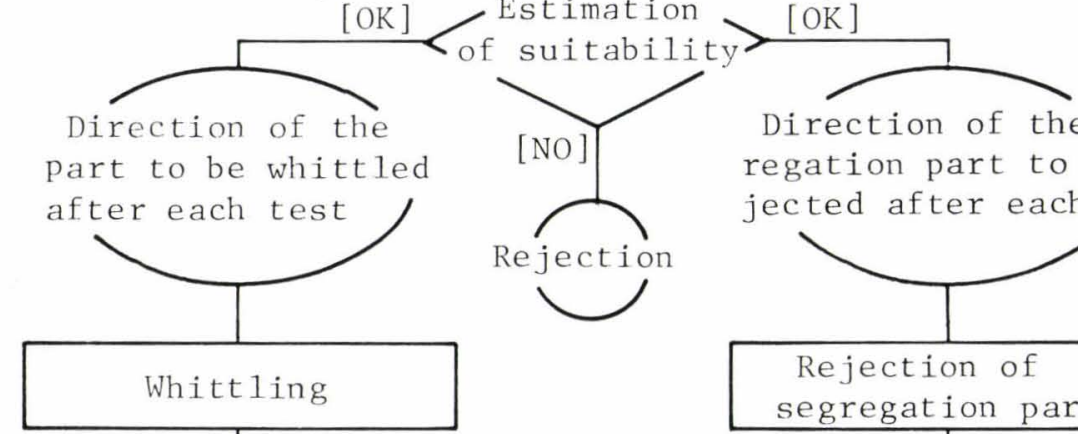

Direction of the segregation part to be rejected after each test
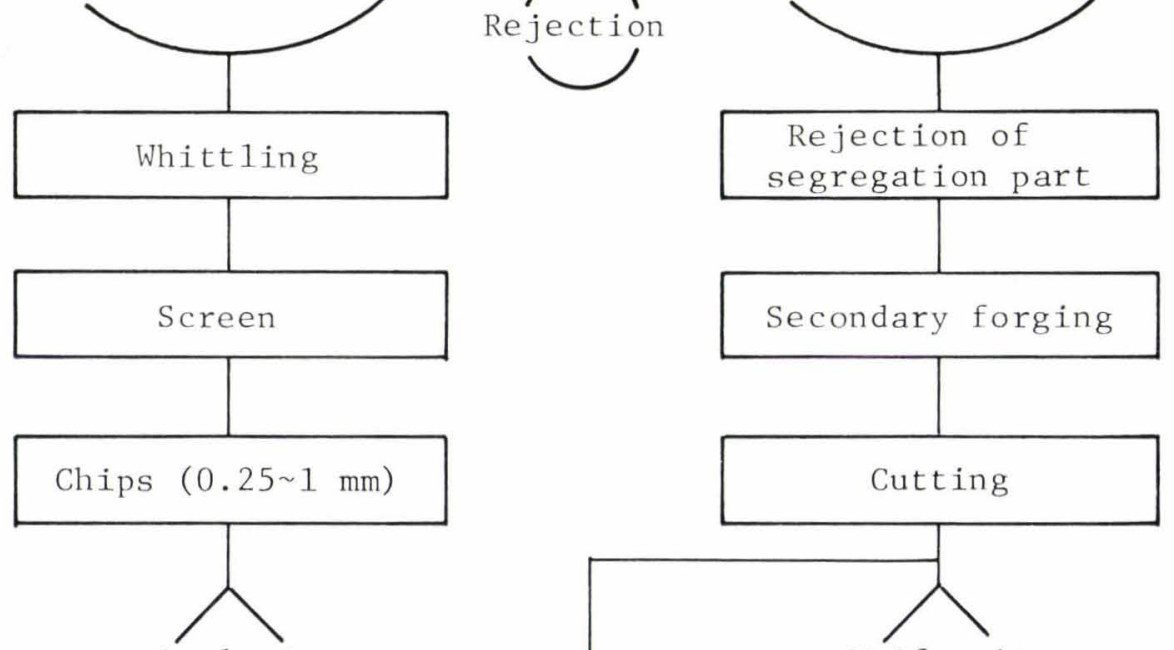

Analysis

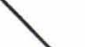
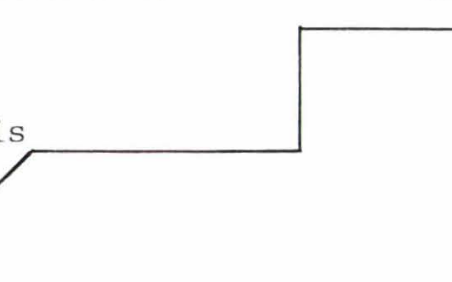

Secondary forging

Fig. 1. Preparation process of Minor Element Series B 
Table 2. Chemical composition of NBS and BAS standards (\%)

\begin{tabular}{|c|c|c|c|c|c|c|c|c|c|c|c|}
\hline Element & $\begin{array}{l}\text { NBS } \\
1161\end{array}$ & $\begin{array}{l}\text { NBS } \\
1162\end{array}$ & $\begin{array}{l}\text { NBS } \\
1163\end{array}$ & $\begin{array}{l}\text { NBS } \\
1164\end{array}$ & $\begin{array}{l}\text { NBS } \\
1166\end{array}$ & $\begin{array}{l}\text { NBS } \\
1167\end{array}$ & $\begin{array}{l}\text { NBS } \\
1168\end{array}$ & $\begin{array}{c}\text { BAS } \\
\text { SS-50 }\end{array}$ & $\begin{array}{c}\text { BAS } \\
\text { SS-59 }\end{array}$ & $\begin{array}{c}\text { BAS } \\
\text { SS-432 }\end{array}$ & Range \\
\hline C & 0.15 & {$[0.40]$} & 0.19 & {$[0.54]$} & 0.065 & 0.11 & {$[0.26]$} & $(0.22)$ & $(0.16)$ & 0.093 & $0.065 \sim 0.19$ \\
\hline $\mathrm{Mn}$ & 0.36 & 0.94 & 1.15 & 1.32 & 0.113 & 0.275 & 0.47 & $(0.19)$ & 0.12 & 1.10 & \\
\hline $\mathrm{P}$ & 0.053 & 0.045 & 0.031 & 0.017 & 0.012 & 0.033 & 0.023 & $(0.019)$ & $(0.029)$ & 0.016 & \\
\hline $\mathrm{S}$ & $(0.02)$ & $(0.02)$ & $(0.02)$ & $(0.02)$ & $(0.01)$ & $(0.01)$ & $(0.02)$ & $(0.009)$ & $(0.021)$ & 0.053 & \\
\hline $\mathrm{Ni}$ & {$[1.73]$} & {$[0.70]$} & {$[0.39]$} & 0.135 & 0.051 & 0.088 & {$[1.03]$} & 0.022 & & {$[0.24]$} & $0.022 \sim 0.135$ \\
\hline $\mathrm{Cr}$ & 0.13 & {$[0.74]$} & {$[0.26]$} & 0.078 & {$[0.011]$} & 0.036 & {$[0.54]$} & 0.131 & & {$[0.21]$} & $0.036 \sim 0.131$ \\
\hline Mo & {$[0.30]$} & 0.080 & 0.12 & 0.029 & 0.011 & 0.021 & {$[0.20]$} & {$[0.22]$} & & 0.039 & $0.011 \sim 0.120$ \\
\hline V & 0.024 & 0.058 & 0.10 & {$[0.295]$} & 0.007 & 0.041 & {$[0,17]$} & & 0.083 & & $0.007 \sim 0.10$ \\
\hline Co & {$[0.26]$} & {$[0.11]$} & 0.013 & 0.028 & 0.046 & 0.074 & {$[0.16]$} & & 0.070 & & $0.013 \sim 0.074$ \\
\hline $\mathrm{Ti}$ & $(0.01)$ & 0.037 & 0.010 & 0.004 & 0.057 & {$[0.26]$} & 0.011 & 0.021 & & & $0.004 \sim 0.057$ \\
\hline As & 0.028 & 0.046 & {$[0.10]$} & 0.018 & 0.014 & {$[0.14]$} & 0.008 & 0.031 & & & $0.008 \sim 0.046$ \\
\hline $\mathrm{Sn}$ & 0.022 & 0.066 & 0.013 & 0.043 & 0.005 & 0.10 & 0.009 & 0.085 & & 0.016 & $0.005 \sim 0.085$ \\
\hline $\mathrm{B}$ & 0.0002 & 0.0005 & 0.0012 & 0.005 & $(0.0002)$ & $(0.0002)$ & {$[0.009]$} & & {$[0.008]$} & & $0.0002 \sim 0.005$ \\
\hline $\mathrm{Nb}$ & 0.011 & 0.096 & {$[0.195]$} & 0.037 & 0.005 & {$[0.29]$} & 0.006 & & & 0.029 & $0.005 \sim 0.096$ \\
\hline $\mathrm{Zr}$ & $(<0.005)$ & 0.063 & 0.20 & 0.010 & $(<0.005)$ & 0.094 & $(<0.005)$ & & & & $0.005 \sim 0.094$ \\
\hline
\end{tabular}

( ): Uncertified value

[ ]: Standard value, not used for the calculation in this work

analysis causes difference between standard samples. So the disc was prepared according to Fig. 1; the segregation parts were cut and rejected and then the steel samples remained were forged into round stick (35 $\mathrm{mm} \phi$ ) samples (the secondary sample). Test portions quarried from them were checked by emission spectroscopy and it was certified that the samples had good precision.

This series has been produced at Research Laboratories of Kawasaki Steel Corp. in Japan.

\section{Results of Segregation Test}

The procedure is established as follows as the rules of the Committee on Iron and Steel Standard Samples for Analysis about the examination of constituent segregation within and between samples:

"Uniformity of standard samples for instrumental analysis should be confirmed by an appropriate instrumental analysis for one-tenth of whole samples at a laboratory in charge of production."

So, the following examination of segregation within and between samples was performed according to the method $^{3)}$ established cooperatively by the Photoelectric Emission Spectroscopic Analysis Subcommittee in the Iron and Steel Analysis Committee, the Joint Research Society of the Iron and Steel Institute of Japan.

Ten samples from NBS and BAS standards within the range of the content of Minor Element Series B (hereinafter indicate 'comparative samples') were used to compare with the Japanese samples. Chemical compositions of the comparative samples are shown in Table 2. The non-standardized values are in parentheses and the standard values which are out of the range of the content of this series and not used for calculation in this work, in brackets.

Apparatus and analytical conditions are listed in Table 3 and analytical lines in Table 4 .
Table 3. Apparatus and analytical conditions

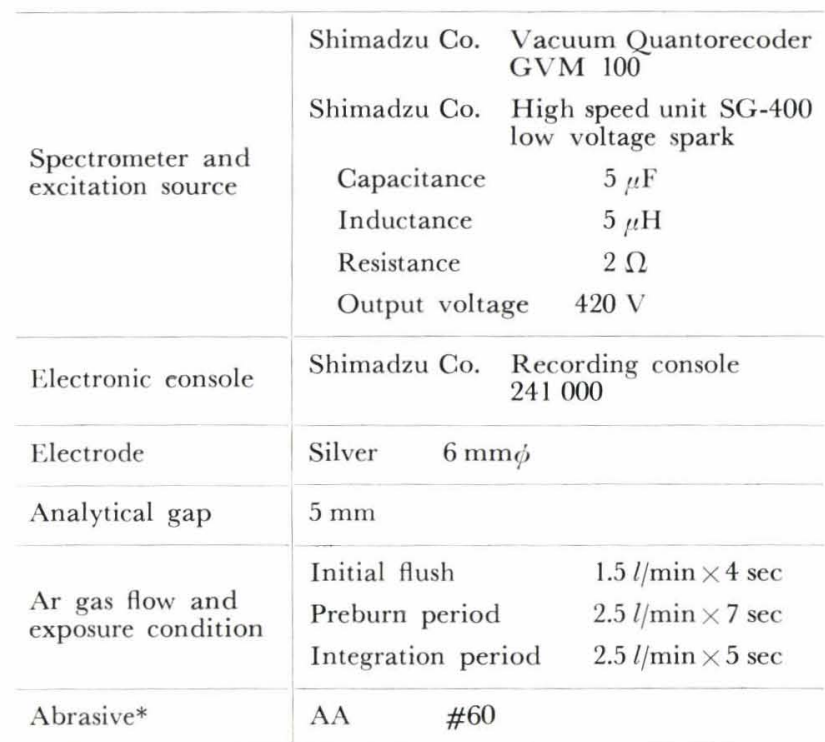

* Preparation of Sample: The surface of the sample for the determination of aluminum is finished with a dry silicon carbide abrasive belt of 80 grit.

Table 4. Analytical lines

\begin{tabular}{|c|c|c|c|c|c|}
\hline \multirow{2}{*}{$\begin{array}{l}\text { Element } \\
\text { Carbon }\end{array}$} & \multicolumn{2}{|c|}{$\begin{array}{l}\text { Wave length } \\
(\AA)\end{array}$} & \multirow{3}{*}{$\begin{array}{l}\text { Element } \\
\text { Arsenic } \\
\text { Tin }\end{array}$} & \multicolumn{2}{|c|}{$\begin{array}{c}\text { Wave length } \\
(\AA)\end{array}$} \\
\hline & $\mathrm{C}$ & 1930.9 & & As & 1972.6 \\
\hline Nickel & $\mathrm{Ni}$ II & 2316.0 & & Sn II & 1899.9 \\
\hline Chromium & Cr II & 2677.2 & Boron & B & 1826.4 \\
\hline Molybdenum & Mo & 2020.3 & Niobium & Nb II & 3195.0 \\
\hline Vanadium & V II & 3110.7 & Zirconium & $\mathrm{Zr}$ II & 3392.0 \\
\hline Cobalt & Co I & 3453.5 & Calcium & Ca II & 3933.7 \\
\hline Titanium & Ti II & 3372.8 & Iron & $\mathrm{Fe} \mathrm{II}$ & 2714.4 \\
\hline Aluminum & $\mathrm{Al}$ & 3961.5 & & & \\
\hline
\end{tabular}




\section{Segregation within Sample}

Firstly, each element in the comparative samples was determined by emission spectroscopic method with a daily-work calibration curve. The emission was detected from four points on one analyzing surface.

The average $\left(A_{N}\right)$ and standard deviation $\left(\sigma_{w_{N}}\right)$ were calculated from obtained values. The simple regression equation for the relation between $\sigma_{w N}$ and the corresponding analytical value was obtained. Standard deviation $\left(\sqrt{ } V_{y, x}\right)$ representing fluctuation from the regression curve was obtained. The results are shown in Table 5 with the regression equations.

Then, ten pieces picked up at random from each eight prepared samples were analyzed by the same method as for the comparative samples and average $\left(A_{J}\right)$ and standard deviation $\left(\sigma_{w J}\right)$, as shown in Table 6 , were calculated. $\sigma_{w c J}$ was calculated by substituting a standard value of prepared sample into the equation in Table 5.

The result of the comparison between $\sigma_{w J}$ and $\sigma_{w c J}$ is expressed as the mark of $a, b$ or $c$ at right shoulder of $\sigma_{w J}$ in Table 6 . Values marked with $a, b$ and $c$ are respectively for the case of $\sigma_{w J} \leq \sigma_{w c J}+$ $\sqrt{V_{y, x}}, \sigma_{w c J}+\sqrt{ } V_{y, x}<\sigma_{w J} \leq \sigma_{w c J}+2 \sqrt{ } V_{y x}$ and $\sigma_{w J}>$ $\sigma_{w c J}+2 \sqrt{ } V_{y x}$. Most of them were marked with $a$. So, the samples of Minor Element Series B were confirmed to be excellent as standard samples for spectroscopic analysis.

$\sigma_{w N}$ for calcium was not obtained because no indication of the standard value was given for the comparative sample and the determination of antimony was impossible for low sensitivity at measurement.

$\sigma_{w J}$ for calcium was calculated from the results of the prepared samples, and is added to Table 6 .

Samples without a mark in Table 6 could not be compared with the comparative samples because the content was beyond that of the comparative samples.

Table 6. Test results on segregation within

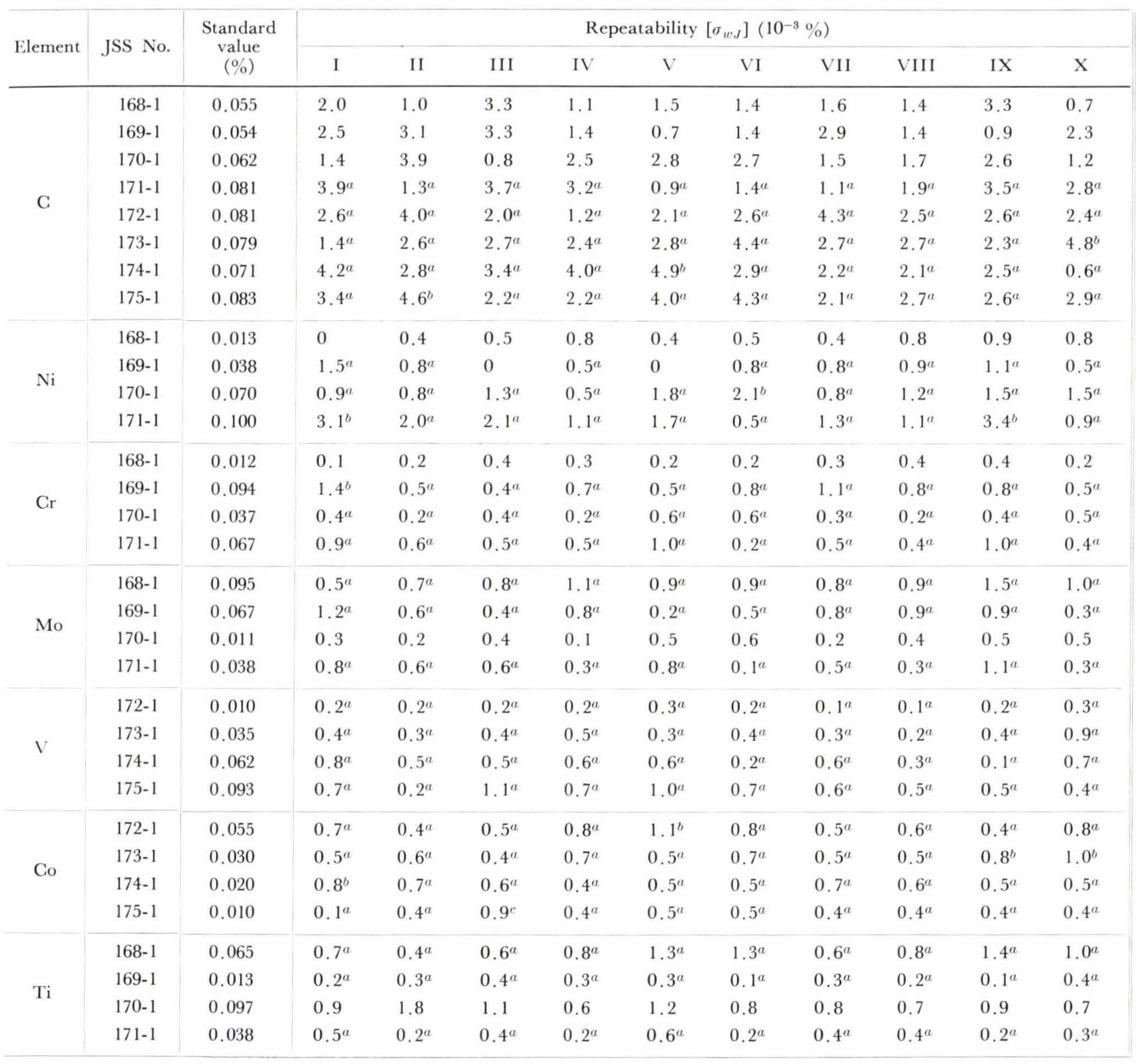


Table 5. Calculating formulas of the measurement repeatability in a sample derived from the results of the comparative sample

\begin{tabular}{|c|c|c|c|}
\hline Element & $\begin{array}{c}\text { Concentration range } \\
(\%)\end{array}$ & Formula & $\begin{array}{l}\text { Root-dispersion } \\
\left(\sqrt{V_{y x}}\right)\end{array}$ \\
\hline C & $0.065 \sim 0.19$ & $\sigma_{w N}=0.00149+0.0265 \% \mathrm{C}$ & 0.00104 \\
\hline $\mathrm{Cr}$ & $0.036 \sim 0.131$ & $\sigma_{w N}=0.00054+0.0035 \% \mathrm{Cr}$ & 0.00028 \\
\hline Mo & $0.011 \sim 0.120$ & $\sigma_{w N}=0.00021+0.0193 \% \mathrm{Mo}$ & 0.00031 \\
\hline V & $0.007 \sim 0.10$ & $\sigma_{w N}=0.00013+0.0144 \% \mathrm{~V}$ & 0.00035 \\
\hline Co & $0.013 \sim 0.074$ & $\sigma_{w N}=0.00015+0.0126 \%$ Co & 0.00030 \\
\hline $\mathrm{Ti}$ & $0.004 \sim 0.057$ & $\sigma_{w s}=-0.00003+0.0357 \% \mathrm{Ti}$ & 0.00040 \\
\hline $\mathrm{Al}$ & $0.005 \sim 0.058$ & $\sigma_{w N}=0.00056+0.0058 \% \mathrm{Al}$ & 0.00030 \\
\hline As & $0.008 \sim 0.046$ & $\sigma_{w N}=0.00160+0.0145 \% \mathrm{As}$ & 0.00053 \\
\hline Sn & $0.005 \sim 0.085$ & $\sigma_{w N}=0.00039+0.0101 \% \mathrm{Sn}$ & 0.00031 \\
\hline B & $0.0002 \sim 0.005$ & $\sigma_{w N}=0.000032+0.0466 \% \mathrm{~B}$ & 0.00028 \\
\hline $\mathrm{Zr}$ & $0.005 \sim 0.094$ & $\sigma_{w N}=0.00128+0.0255 \% \mathrm{Zr}$ & 0.00084 \\
\hline
\end{tabular}

sample by emission spectroscopic analysis

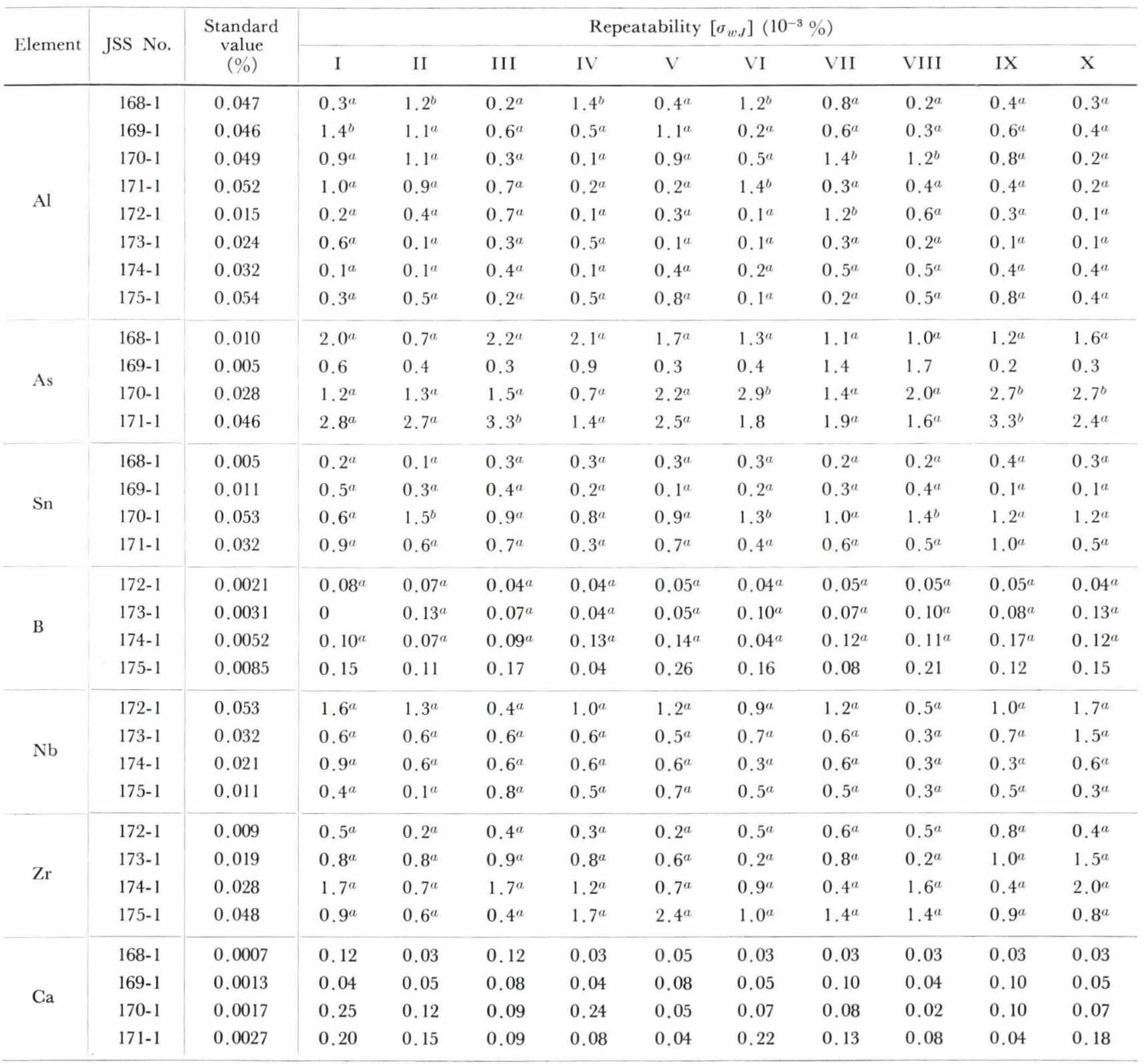




\section{Segregation between Sample}

The fluctuation of the content between samples was investigated according to Section $I V$. 1. Each element concentration was determined by emission from four points on one analyzing surface and the average $\left(A_{N 1}\right)$ of the results was obtained, and then the analyzed surface was polished. The determination was repeated ten times by the same procedure and averages $\left(A_{N 1} \sim A_{N 10}\right)$ and their standard deviations $\left(\sigma_{b N}\right)$ were calculated.

Then the simple regression equation for the relation between $\sigma_{b N}$ and the corresponding analytical value was obtained, and the standard deviations $\left(\sqrt{ } V_{y, x}\right)$ were obtained according to Section $I V$. 1, shown in Table 7.

$\sigma_{b J}$ was calculated from ten pieces of $A_{J}$ for the sample randomly obtained at Section $I V$. 1 , and $\sigma_{b c J}$ was calculated by substituting a standard value into the equation in Table 7 . Results of the comparison between $\sigma_{b J}$ and $\sigma_{b c J}$ were represented by the shoulder mark of $a, b$ and $c$ (Table 8).
Though $\sigma_{b c J}$ for the comparative sample was obtained from the results of repeated determinations on the same sample and $\sigma_{b J}$ for the prepared sample was obtained from the results of determinations on ten samples, most of $\sigma_{b J}$ were marked " $a$ " and it was confirmed that this series had a small segregation and good suitability as standard samples.

\section{Calibration Curve}

Figure 2 shows some calibration curves for the determinations of Minor Element Series B and Standardization Series A by emission spectroscopic method under the conditions represented in Table 3.

It is known that metallurgical history or inclusions and precipitates present in steel affect the emission spectroscopic analysis. So, in addition to this series other standard series is desired to be used for drawing a calibration curve corresponding to property, content and metallurgical history of objective steel at each laboratory.

The calibration curve for boron of this series was

Table 7. Calculating formulas of the measurement repeatability between samples derived from the results of the comparative sample

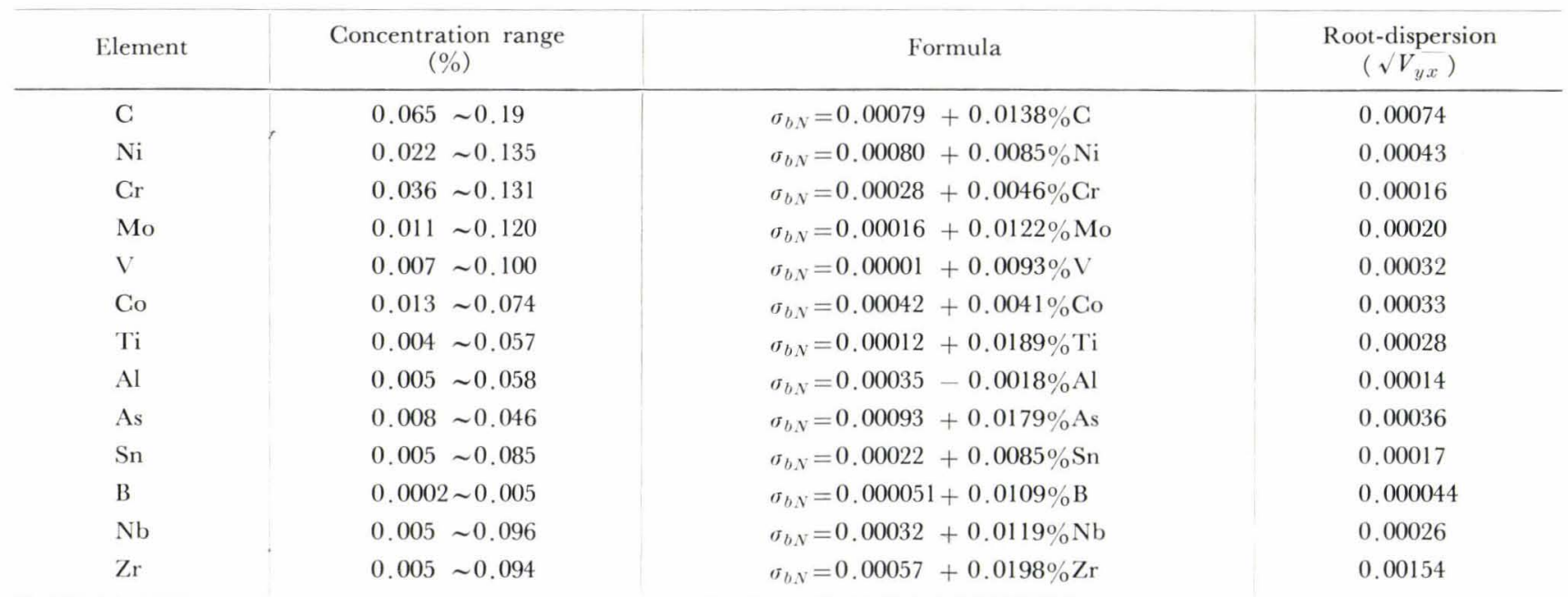

Table 8. Test results on segregation between samples by emission spectroscopic analysis

\begin{tabular}{|c|c|c|c|c|c|c|c|c|}
\hline \multirow{2}{*}{ Element } & \multicolumn{8}{|c|}{ Repeatability $\left[\sigma_{w, J}\right]\left(10^{-3} \%\right)$} \\
\hline & $168-1$ & $169-1$ & $170-1$ & $171-1$ & $172-1$ & $173-1$ & $174-1$ & $175-1$ \\
\hline $\mathrm{C}$ & 2.9 & 2.2 & 1.8 & $3.2^{b}$ & $3.3^{b}$ & $3.2^{b}$ & $2.3^{a}$ & $3.3^{b}$ \\
\hline $\mathrm{Ni}$ & 0.8 & $1.1^{a}$ & $0.9^{a}$ & $2.4^{b}$ & & & & \\
\hline $\mathrm{Cr}$ & 0.5 & $1.0^{b}$ & $0.4^{a}$ & $0.3^{a}$ & & & & \\
\hline Mo & $1.2^{a}$ & $0.9^{a}$ & 0.3 & $0.5^{a}$ & & & & \\
\hline $\mathrm{V}$ & & & & & $0.1^{a}$ & $0.4^{a}$ & $0.6^{a}$ & $0.5^{a}$ \\
\hline Co & & & & & $0.4^{a}$ & $0.5^{a}$ & $0.4^{a}$ & $0.3^{a}$ \\
\hline $\mathrm{Ti}$ & $0.9^{a}$ & $0.2^{a}$ & 0.8 & $0.5^{a}$ & & & & \\
\hline $\mathrm{Al}$ & $0.4^{a}$ & $0.2^{a}$ & $0.2^{a}$ & $0.3^{a}$ & $0.4^{b}$ & $0.3^{u}$ & $0.3^{a}$ & $0.3^{a}$ \\
\hline As & $1.8^{\prime}$ & $1.1^{a}$ & $1.3^{a}$ & $2.2^{a}$ & & & & \\
\hline $\mathrm{Sn}$ & $0.4^{a}$ & $0.4^{a}$ & $0.5^{a}$ & $0.5^{a}$ & & & & \\
\hline $\mathrm{B}$ & & & & & $0.07^{a}$ & $0.05^{a}$ & $0.06^{a}$ & $0.12^{a}$ \\
\hline $\mathrm{Nb}$ & & & & & $0.7^{a}$ & $0.5^{a}$ & $0.6^{a}$ & $1.8^{a}$ \\
\hline $\mathrm{Zr}$ & & & & & $0.4^{a}$ & $0.9^{a}$ & $0.8^{a}$ & $0.4^{a}$ \\
\hline $\mathrm{Ca}$ & 0.04 & 0.08 & 0.05 & 0.12 & & & & \\
\hline
\end{tabular}



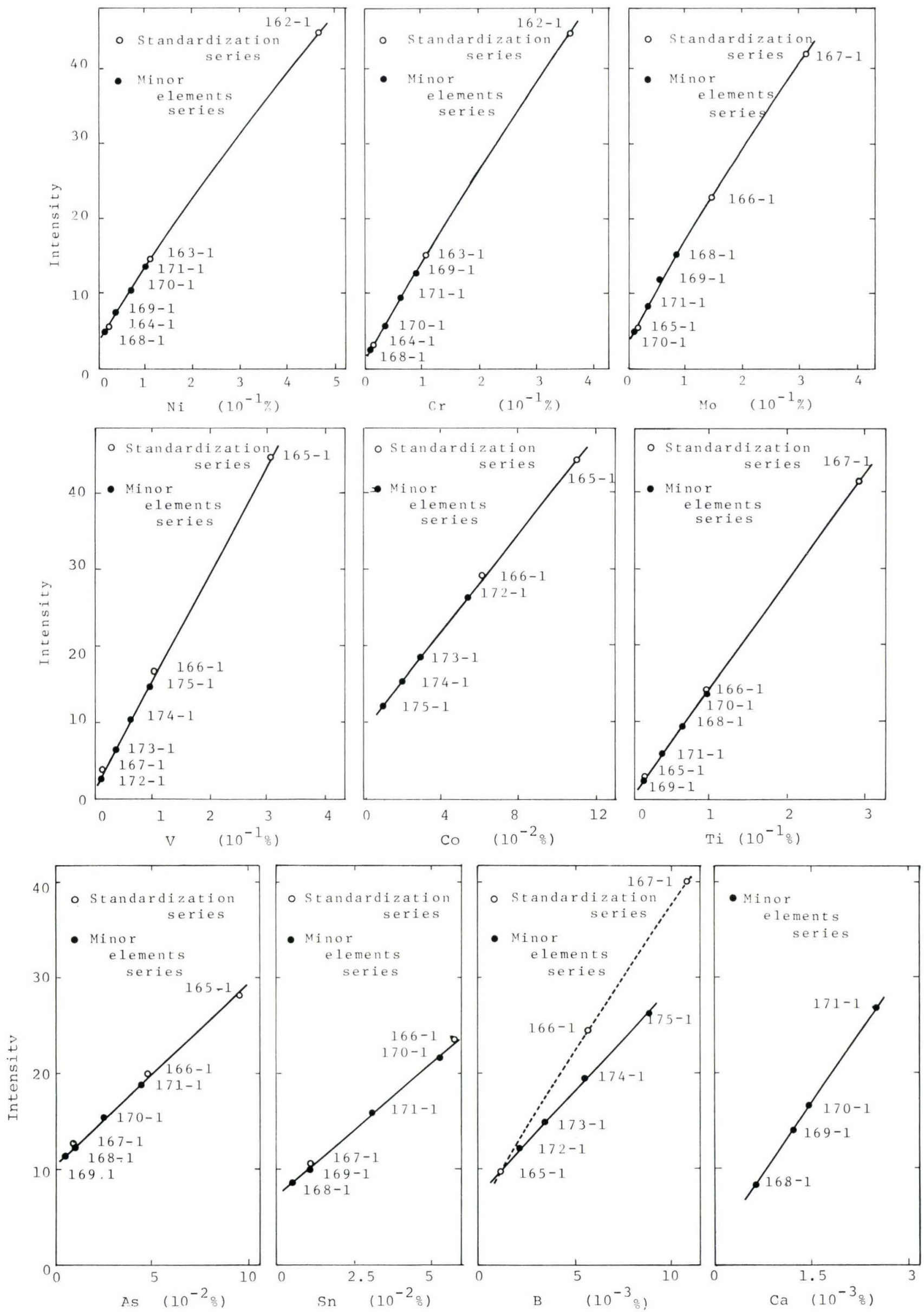

Fig. 2. Calibration curve for each element in the sample of Minor Element Series B and Standardization Series A by emission spectroscopic method 


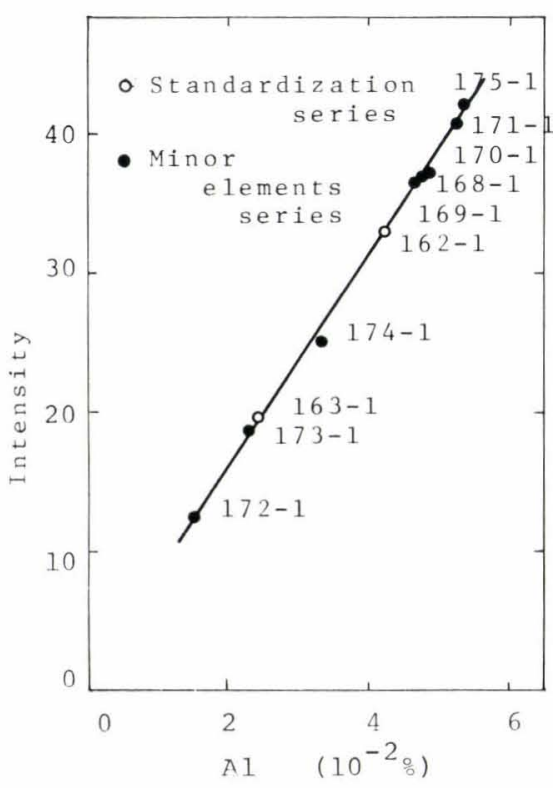

A1 $\quad\left(10^{-2} \frac{\mathrm{o}}{\mathrm{o}}\right)$

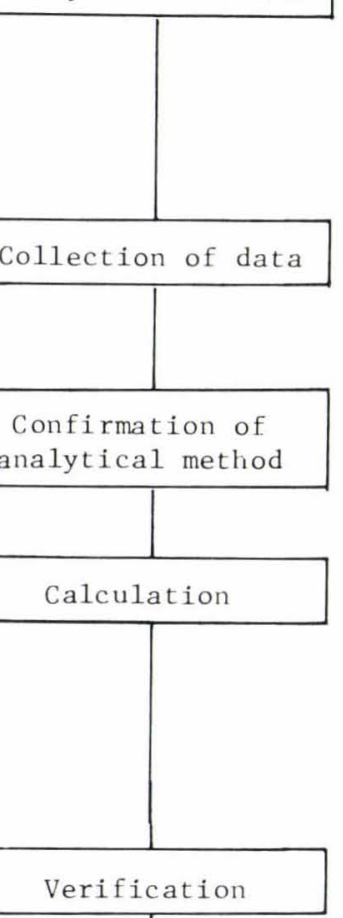

Decision of standard value
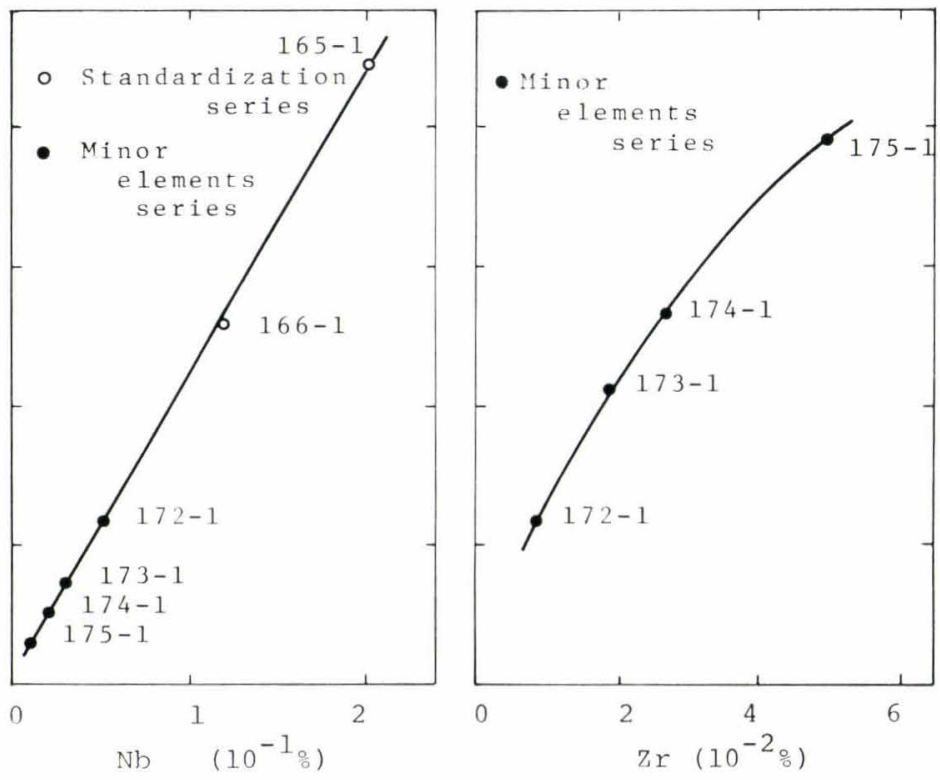

Fig. 2. Continued

10 11 Analysts ( The analysis section of university and goverment and municipal office, the analysis section or laboratory of steel maker)

Results of duplicate analyses separately (Since 1975 , it has been revised to "duplicate analyses at the same time." )

The Iron and Steel Institute of Japan

The Secretariat of the Committee on Iron and Steel Standard Samples for Analysis.

JIS methods or equivalent ones are used, and if nesessary, the presentation of related paper is required.

Calculation note for the decision of standard values

a) Average in each laboratory $(\bar{x})$

b) General average ( $\overline{\bar{x}}$ )

c) Range in each laboratory ( R )

d) Standard deviation of average

in each laboratory $\quad(\sigma \overline{\mathrm{x}})$

e) Range ( $\operatorname{Rmax})$

a) Estimation of tolerance error in each laboratory

b) $2 \sigma$ verification --- average in each laboratory $(\overline{\mathrm{x}})$ is to be within $[\overline{\overline{\mathrm{x}}} \pm 2 \sigma \overline{\mathrm{x}}]$.

c) Rmax verification --- For new standard samples, the ratio of range maximum of them to the standard devation of old standard samples is not to be beyond the limit defined.

d) Technical estimation --- The estimation in technical aspect is added to the statistical verification.

The subcommittee of the Committee on Iron and Steel Standard Samples for Analysis.

The averages shown in Cetificate are the arithmetric mean calculated from the remain not rejected by each verification.

( Since 1975, the standard deviations of the data adopted have been added. )

Fig. 3. Procedure for the decision of standard value 
different from that of Standardization Series, and it seemed that the metallurgical history or the state of precipitates and inclusions present in steel had effects on the determinations (the studies about this has been going on). For all the elements except boron, however, each analytical value of an element was plotted on one calibration curve.

\section{Decision of Standard Value}

The method for the decision of standard values of Japanese Standard Sample for Iron and Steel is described in the rules of the Committee on Iron and Steel Standard Samples for Analysis. Figure 3 shows the procedure.

JIS (Japanese Industrial Standard) method or equivalent ones should be applied as analytical method because it is defined by JIS K0501 (general rules for chemical standards material) that a standard sample belongs to 'Component Standard Material' and the content should be determined by the method prescribed in JIS.

Recently, however, some other methods have been adopted in consideration of kinds of steel and involved elements, after suitability for analytical method had been studied at each laboratory. The use of various analytical methods for the decision may give accurate values without the specific tendency by a particular one method.

Moreover, the analytical methods adopted most frequently coincide with the method which had been studied thoroughly by Iron and Steel Analysis Committee, Joint Research Society, ISIJ, ISO/TC 17/SC 1 (Iron and Steel Analysis) Committee in Japan.

The analytical methods adopted for the decision of standard values are shown in Table 9, and the simple regression equations of standard deviation $\left(\sigma_{\overline{\mathrm{x}}}\right)$ in the measurement for the decision of standard value in Table 10.

\section{Conclusion}

The production and quality of Minor Element Series B of Japanese Standard Samples for Iron and Steel Analysis are described.

The standard samples are confirmed to be not inferior to comparative samples of NBS No. 1160 series and BAS SS samples for spectrometric analysis.

The problem to be solved further is that the calibration curve for boron of this series is different from that of the Standardization Series. This is now being studied and it will result in a satisfactory settlement by the Subcommittee of the Committee on Iron and Steel Standard Samples for Analysis.

The method of decision of the standard value and the precision for analysis of trace amounts of elements

Table 9. Analytical methods used for the determination of standard values

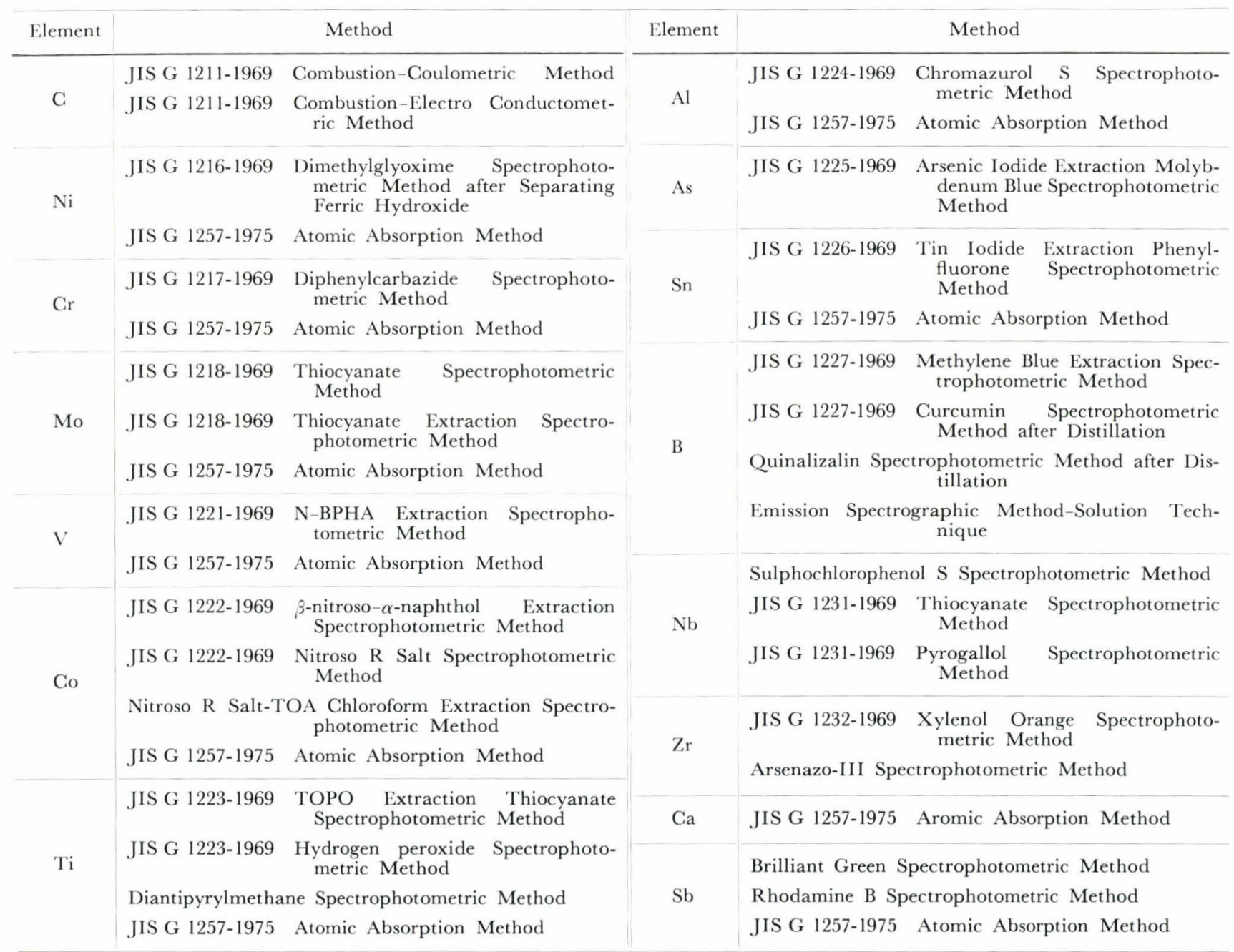


Table 10. Calculating formulas of reproducibility on the measurement for the determination of standard values

\begin{tabular}{l|lll}
\hline Element & $\begin{array}{c}\text { Concentration } \\
\text { range }(\%)\end{array}$ & \multicolumn{1}{|c}{ Formula $(\%)$} \\
\hline $\mathrm{Ni}$ & 0.01 & $\sim 0.10$ & $0.00121+0.0088 \times\{\mathrm{Ni}(\%)\}$ \\
$\mathrm{Cr}$ & 0.01 & $\sim 0.10$ & $0.00045+0.0253 \times\{\mathrm{Cr}(\%)\}$ \\
$\mathrm{Mo}$ & 0.01 & $\sim 0.10$ & $0.00069+0.0168 \times\{\mathrm{Mo}(\%)\}$ \\
$\mathrm{V}$ & 0.01 & $\sim 0.10$ & $0.00039+0.0236 \times\{\mathrm{V}(\%)\}$ \\
$\mathrm{Co}$ & 0.01 & $\sim 0.05$ & $0.00030+0.0303 \times\{\mathrm{Co}(\%)\}$ \\
$\mathrm{Ti}$ & 0.01 & $\sim 0.10$ & $0.00072+0.0203 \times\{\mathrm{Ti}(\%)\}$ \\
$\mathrm{Al}$ & 0.01 & $\sim 0.05$ & $0.00104+0.0116 \times\{\mathrm{Al}(\%)\}$ \\
$\mathrm{As}$ & 0.01 & $\sim 0.05$ & $0.00023+0.0390 \times\{\mathrm{As}(\%)\}$ \\
$\mathrm{Sn}$ & 0.01 & $\sim 0.05$ & $0.00051+0.0333 \times\{\mathrm{Sn}(\%)\}$ \\
$\mathrm{B}$ & $0.002 \sim 0.01$ & $0.00019+0.0137 \times\{\mathrm{B}(\%)\}$ \\
$\mathrm{Nb}$ & 0.01 & $\sim 0.05$ & $0.00023+0.0401 \times\{\mathrm{Nb}(\%)\}$ \\
$\mathrm{Zr}$ & 0.01 & $\sim 0.05$ & $0.00109+0.0185 \times\{\mathrm{Zr}(\%)\}$ \\
$\mathrm{Ca}$ & $0.0005 \sim 0.003$ & $0.00007+0.0443 \times\{\mathrm{Ca}(\%)\}$ \\
$\mathrm{Sb}$ & $0.002 \sim 0.02$ & $0.00014+0.0301 \times\{\mathrm{Sb}(\%)\}$ \\
& & &
\end{tabular}

are mentioned.

\section{Acknowledgements}

The author is indebted to Dr. T. Ikeno, Chairman, and Mr. T. Otsuki, Secretary of the Committee on Iron and Steel Standard Samples for Analysis, for their helpful discussion.

\section{REFERENCES}

1) Progress of Japanese Standard Samples of Iron and Steel, ed. by ISIJ, Tokyo, (1977).

2) T. Ikeno and T. Otsuki: Tetsu-to-Hagané, 60 (1974), 1968.

3) K. Okazaki and I. Kawashima: Tetsu-to-Hagané, 58 (1972), 533. 